\title{
Processo Legislativo para além do Parlamento em Estados Autoritários: uma análise comparada entre os Códigos Penais Italiano de 1930 e Brasileiro de 1940
}

\author{
Legislative Proceedings beyond the Parliament in Authoritarian States: a \\ comparative analysis between the 1930 Italian and 1940 \\ Brazilian Criminal Codes
}

Diego Nunes

Universidade Federal de Uberlândia, Uberlândia - MG, Brasil

Resumo: Neste trabalho será utilizada a experiência das reformas penais realizadas pelo fascismo e o "Estado Novo" para compreender a legitimação constitucional de afastar o parlamento e a colaboração de renomados penalistas para a confecção das codificações sem o controle da representação popular. Analisando documentos de época como os projetos de lei e a historiografia penal, concluiu-se que, na Itália, o parlamento abdicou da competência via delegação de poderes ao governo, e, no Brasil, o golpe de Estado outorgou nova constituição cuja competência foi destinada ao Poder Executivo. Além disso, ambos os regimes valeram-se da legitimação intelectual dos juristas.

Palavras-chave: Processo Legislativo. Código Penal. Autoritarismo
Abstract: This paper aims to analyze the experience of the criminal reforms carried out by the Italian fascism and the Brazilian "Estado Novo", to understand the constitutional legitimacy for the parliament's dismissal and the collaboration of renowned lawyers for codemaking, but without the ultimate control of popular representation. Analyzing the historical documents as the code-drafts and the criminal historiography, this paper concludes that in Italy, the parliament itself has abdicated its competence by a delegation of powers to the government and in Brazil, the 1937 coup d'État imposed a new constitution in which the $\mathrm{x}$ legislative competence fully to the Executive Power. Furthermore, both the regimes used intellectual legitimacy by jurists.

Keywords: Legislative Proceedings. Criminal Code. Authoritarianism.

Recebido em: 30/03/2016

Revisado em: 19/09/2016

Aprovado em: 30/09/2016 


\section{Introdução}

Apesar dos parlamentos pós-Revolução Francesa serem designados pelas constituições como "Poder Legislativo", por muitas vezes tal atribuição foi questionada. Portanto, legislar fora do parlamento, ou mais exatamente deslocar a competência legislativa do parlamento ao governo não é algo inédito, mas possui uma densidade própria em se tratando de regimes autoritários.

A Itália pós-unificação utilizou amplamente o expediente de delegação legislativa para a confecção de suas codificações ${ }^{1}$. O modo como ela foi gerida em 1925 para a reforma penal por parte do fascismo é que a torna particular. Da mesma forma o Brasil: mesmo o código penal anterior não tendo passado pelo crivo parlamentar ${ }^{2}$, o método escolhido para a reforma penal do Estado Novo apresenta peculiaridades a serem exploradas.

Existem alguns trabalhos que analisam a relação entre regimes políticos autoritários e a codificação penal por eles produzida (SBRICCOLI, 2009), mas não na perspectiva comparada. Ainda, a historiografia não se debruçou a fundo sobre a transferência da competência legislativa do parlamento para o executivo como forma de execução de um projeto autoritário de legislação penal, como o "Estado Novo" brasileiro e o fascismo italiano.

Há considerável literatura que passa de modo tangencial pelo argumento. Dentre tantos, cabe citar um discurso do jurista Piero Calamandrei (1966), que ao tratar da função legislativa sob o fascismo aponta como o parlamento se encontrava submisso ao governo fascista que se via como restaurador da legalidade abandonada, advertindo a necessidade de se fazer a historiografia desse fenômeno. É o que se buscará fazer, ainda que

\footnotetext{
${ }^{1}$ Cfr., por exemplo, Sbriccoli (2009) e Latini (2005).

${ }^{2}$ Decreto n. 847, de 11 de outubro de 1890, "Promulga o Codigo Penal. O Generalissimo Manoel Deodoro da Fonseca, Chefe do Governo Provisorio da Republica dos Estados Unidos do Brazil, constituido pelo Exercito e Armada, em nome da Nação, tendo ouvido o Ministro dos Negocios da Justiça, e reconhecendo a urgente necessidade de reformar o regimen penal, decreta o seguinte Codigo Penal dos Estados Unidos do Brazil". Cfr. Sontag (2014, p. 173 e 181).
} 
de modo pontual, neste trabalho, ou seja, apresentar os mecanismos de deslocamento da competência legislativa do parlamento para o governo no fascismo e no Estado Novo que permitiram a tais regimes autoritários brasileiro e italiano como meio para a realização de uma reforma penal de caráter "técnico-autoritário", posto o papel expressivo dos juristas na construção de um projeto jurídico em que o jurista técnico faz as vezes de legislador ${ }^{3}$.

Assim, dada a pertinência de uma pesquisa historiográfico-jurídica sobre a transferência da competência legislativa do parlamento para o executivo como forma de execução de um projeto autoritário de legislação penal, como o "Estado Novo" brasileiro e o fascismo italiano, em que será analisado o caso dos códigos penais italiano de 1930 e o brasileiro de 1940 .

Para tanto, o presente trabalho percorrerá duas frentes. Num primeiro momento, buscar-se-á compreender os mecanismos utilizados por cada um dos regimes para a obtenção de legitimação constitucional para o afastamento do parlamento, visto que ambos se valeram de embasamento legal - a delegação na Itália e a nova constituição no Brasil. Após, dado que ambos os regimes valeram-se da tradicional colaboração de renomados juristas para a confecção das codificações sem o controle final da representação popular, buscar-se-á compreender o papel desse legislador-jurista técnico na conformação de um novo sistema penal.

\section{A Legitimação Constitucional para o Afastamento do Parlamento}

Brasil e Itália trilharam caminhos diversos para que suas codificações penais escapassem das mãos do parlamento. Enquanto na Itália ocorreu uma transferência pontual de competência do Legislativo para o

\footnotetext{
${ }^{3}$ Esse papel do penalista foi caracterizado por Sbriccoli (2009) como "civilistica penale", que parecer ser extensível do campo da "ciência jurídica" para o palco da (tecno) política, quando o jurista faz as vezes de legislador. Sobre como isso era diferente da postura de participação advogada por um Francesco Carrara, cfr. Sontag (2009). No caso brasileiro, a simbiose entre ciência e política a serviço do autoritarismo, ou como na escusa pósautoritária de Lyra (1975), aproveitando-se dele para o bem do direito.
} 
Executivo, no Brasil o novo ordenamento geral fez de tal deslocamento a regra geral. $\mathrm{O}$ meio utilizado para retirar a competência legislativa do parlamento em cada caso foi uma contingência do modelo de Estado imposta pelo regime. O objetivo, porém, é o mesmo: dar uma demonstração de força reformando um importante ramo do direito.

Convém salientar que tal diferença de forma também se atesta pelo momento em que cada regime se encontrava durante o iter legislativo de suas codificações penais. Entre 1925 e 1930, o fascismo encontrava-se em momento de afirmação. O Estado totalitário estava em vias de transformação. Foi exatamente nesse período que ocorreram as "reformas constitucionais" (SALTELLI, 1926), como a concessão ao Poder Executivo de emanar normas jurídicas e a que ampliava os poderes do Chefe de governo, bem como as reformas eleitorais ${ }^{4}$. Por sua vez, o Estado Novo entre 1937 e 1940 encontrava-se em seu ápice de força. Após derrubar a Constituição de 1934 e impor a Constituição de 1937, Getúlio Vargas conseguiu eliminar do cenário político brasileiro o parlamento, que restava tão somente previsto formalmente. Assim, a legislação ficou ao seu encargo com o auxílio dos ministérios.

\subsection{Itália: delegação legislativa ad hoc}

Formalmente, os atos da "revolução" fascista foram todos legais. Os parlamentares fascistas foram eleitos pelas urnas; a maioria parlamentar deu-se pelas leis eleitorais; os poderes do Executivo eram definidos

\footnotetext{
4 "Da un lato, per lo meno nei prossimi tempi, il futuro Duce non è ancora in grado di affrontare e di esautorare le Camere, che costituirà la pagina più pericolosa per le sorti del regime in fieri; ma soprattutto, egli ha tutto l'interesse a valersi del Legislativo, per realizzare le profonde riforme in chiave autoritaria che sono la piattaforma politica del fascismo, specie dopo che la nota legge Acerbo ha assicurato al partito di maggioranza il controllo delle Camere, riconoscendo i due terzi dei seggi alla lista che ottiene alle elezioni il solo $25 \%$ dei voti. Ecco perciò Mussolini affermare dinanzi alla Camera nella seduta del 26 giugno 1924: “Quale sarà il mio programma? L'ho già detto e lo ripeto. Mi propongo di far funzionare le Camere, il parlamento. Lo ripeto: è mia intenzione di non emettere in avvenire decreti legge, poiché se il governo fa lui stesso le leggi, la Camera non ha più niente da fare'. La flessibilità dello Statuto è dunque l'ideale punto di partenza del fascismo; ma il quadro è destinato a mutare in seguito al definitivo affermarsi del regime." (BIGNAMI, 1997, p. 68).
} 
por meio de leis parlamentares e as delegações legislativas eram devidamente concedidas pelo Legislativo. Porém, tal legalidade era carente no aspecto material.

O fascismo via no princípio de legalidade uma forma de enaltecimento da autoridade do Estado por meio da obediência à legislação. $\mathrm{O}$ argumento já foi muito discutido no âmbito da história do direito penal para compreender a opção italiana de não se valer da derrogação do princípio de legalidade penal, ao contrário da União Soviética e da Alemanha nazista. Aqui se deseja tratar do distanciamento da legalidade como forma de aplicar a lei - rígida como afirmação da autoridade do Estado - da legalidade no procedimento legislativo - flexível para dar um sentido autoritário aos mecanismos da democracia liberal. A lei deveria ser cumprida de modo estrito depois de posta, mas para colocá-la não havia problema em utilizar expedientes heterodoxos que descumpriam o Statuto Albertino por meio de leis ordinárias patentemente inconstitucionais ${ }^{5}$. A esse modo de encarar a lei (da sua concepção à sua aplicação) Calamandrei alcunhou de "il regime dell'illegalità penale".

Por mais que houvesse necessidade ${ }^{7}$ de reformas pelo prolongamento no tempo, havia resistência em se colocar as mãos sobre o Código Zanardelli por tudo aquilo que ele representava, tanto em nível políti-

${ }^{5}$ Vale aqui a crítica de Silvio Trentin, jurista exilado na França durante o fascismo: "Avendo a sua disposizione una camera docile ai suoi ordini, [...] gli sembrò opportuno, anche questa volta, pervenire al suo scopo per la via della "legalità", cioè attraverso 1 trasformazione "legislativa" della norma statutaria. Da un giorno all'altro il suo programma si trovò così rovesciato [...] E' a questo momento che cominciò la legislazione veramente fascista, mediante la quale fu attribuito allo Stato italiano, pur conservando in vigore l'antica, una seconda costituzione politica" (TRENTIN, 1983, p. 142-143).

6 "Di questo carattere veramente originale della dittatura fascista bisognerà che lo storico futuro non si dimentichi mai: la quale non fu una dittatura senza leggi, ma fu anzi una dittatura con molte leggi a doppio fondo, dietro le quali era legalmente organizzato con molta cura un ingegnoso apparato di ipocrisia politica, fatto apposta per annullarle impunemente colla violenza o colla frode" (CALAMANDREI 1966, p. 329-330).

7 "La riforma, dunque, si imponeva. Ogni rivoluzione ha provveduto sempre alla riforma delle leggi fondamentali [...] Considerato dal punto di vista politico, il codice di 1889 possiede quasi tutte le manchevolezze di quella democrazia per la quale e dalla quale era stato formato. Ogni codice penale è figlio del suo tempo. Il progetto di codice penale, batte altre vie e persegue differenti fini” (ROMANO-DI FALCO, 1929, p. 434 e 438). 
$\operatorname{co}^{8}$ como em termos de concepção de ciência jurídica e política criminal (SBRICCOLI, 2009, p. 493ss). Mas era desejo do fascismo colocar-se exatamente como antítese à tradição liberal, o que aumentou o seu desejo de apresentar uma intervenção marcante, justamente por compreender o papel constitutivo do direito penal na sociedade italiana (BETTIOL, 1966, p. 59-60; SBRICCOLI, 2009, p. 591ss).

Pela tradição na confecção dos códigos na Itália pós-unitária, o método adotado seria a delegação legislativa ${ }^{9}$. E assim a requereu o ministro da justiça Alfredo Rocco para os códigos: penal e de processo penal ${ }^{10}$, com uma inovação adotada pela primeira vez na delegação relativa aos códigos de direito privado ${ }^{11}$. Não se apresentou um disegno di legge, que valeria como parâmetro. Restava apenas o discutido nas sessões de aprovação. Não por acaso a delegação saiu com indicações excessivamente amplas. Eventuais desvios do Executivo não poderiam ser remediados porque a fórmula de delegação imobilizou o controle do parlamento, relegado a realizar apenas um parecer consultivo do trabalho.

8 "Le resistenze, d'ordine politico, a una riforma derivano dal fatto che il codice di 1889 è il codice della democrazia parlamentare" (ROMANO-DI FALCO, 1929, p. 433).

${ }^{9}$ Sobre a ideia técnica desse modo de delegação: "Il secondo tipo di leggi di delegazione si verifica quando, il Parlamento si spoglia della facoltà di dettar legge su una data materia e ne investe il Governo dandogli piena facoltà di procedere a quel lavoro legislativo nel modo che reputi migliore e stabilendo che il suo decreto acquisti forza di legge e non possa essere modificato o abrogato che per legge. Il Governo, nel procedere a tal compito, ricorre, di regola, al parere di Commissioni tecniche competenti. Qualche volta le Camere legislative, delegando quel potere al Governo, lo vincolano segnalando i limiti dell'opera sua ed obbligandolo a seguire una data procedura; come, per esempio, quella di sentire il parere di una Commissione o anche indicando tra quali elementi debba essere in tutto o in parte scelta la Commissione stessa." (SALTELLI, 1926, p. 212).

10 “Uno tra i primi atti dell'on. Prof. Alfredo Rocco, nell'assumere la direzione del Ministero della giustizia, fu quello di dare inizio ai lavori per una completa riforma del codice penale e del codice di procedura penale, richiedendo, nel contempo, al Parlamento i necessari poteri di delega [...] I codici sono leggi talmente complesse da non poter essere formati da un corpo legislativo e da non potere essere da esso analiticamente discussi. Tutti i codici sono stati sempre promulgati sulla base di un'ampia delega legislativa concessa dal Parlamento al Governo" (SALTELLI; ROMANO-DI FALCO, 1930, p. 6).

11 Legge 30 dicembre 1923, n. 2.814. 
Durante a tramitação do projeto de delegação, a oposição da Câmara tentou impor balizas mais precisas. De fato, porque esta era a tradição: a delegação é feita, mas o parlamento controla previamente a extensão de tal concessão de poder ${ }^{12}$. Mas a maioria deferiu o pedido de confiança feito pelo ministro Rocco para possuir a mais ampla liberdade de ação, com o objetivo poder realizar as soluções técnicas mais adequadas ${ }^{13}$. Ao fim do ano, no Senato del Regno, Rocco se augura de não ter havido ali discordância ao governo nesta casa com relação ao método utilizado, ao contrário da tramitação na outra casa legislativa.

Rocco fez questão de apresentar viva defesa sobre o modo de delegação empregado no projeto em discussão desde a primeira apresentação na Camera dei Deputati. Ali, defendeu que a complexidade da reforma dos códigos de direito privado demonstrou que o governo necessita de mais poderes para a reforma penal. Insistiu no argumento de que esta delegação era similar às anteriores, inclusive à do código penal de 1889 (ROCCO, 1927, p. 213-214).

Ainda, recorreu ao argumento da impossibilidade de se discutir um código artigo por artigo no parlamento, porque a maioria dos integrantes não teria o conhecimento técnico relativo ao ponto, e principalmente pelo inconveniente temporal, pois tal atividade paralisaria a casa legislativa ${ }^{14}$.

Os discursos de Rocco demonstram que ele era consciente da importância presente na reforma penal, o que o teria motivado a uma re-

\footnotetext{
12 “A volte anzi non solo sono fissati limiti negativi e di estensione ed è stabilito l'oggetto delle disposizioni, ma anche è determinato, in maniera più o meno precisa, il contenuto delle disposizioni, dandosi non solo indicazioni sull'oggetto da regolare, ma anche sul modo con cui l'oggetto deve essere regolato" (ESPOSITO, 1934, p. 134).

13 "E perciò sarei grato alla Camera se non mi vincolasse fin d'ora a soluzioni precise e prego pertanto gli onorevoli proponenti di trasformare i loro ordine del giorno in raccomandazione, raccomandazione che il Governo accetta, il che significa che questi punti saranno seriamente meditati prima di trasformare la disciplina, quale è stata adombrata nella relazione, in precisi articoli di legge. E ciò anche per ragioni tecniche, perche tutti le soluzioni sono suscettibili di diverse formulazioni e possono essere profondamente diverse secondo le formulazioni" (ROCCO, 2005, p. 202).

${ }^{14}$ Para o caso brasileiro, veja-se idêntica situação com o projeto de 1893 (SONTAG, 2014, p. 255ss).
} 
forma mais incisiva, seja pelo radicalismo das modificações, seja pela celeridade empregada para dar cabo a tal tarefa. Todavia, o mandato de delegação legislativa era para emendar o código, e não elaborar um novo. O silêncio quanto a tal questão, seja nas fontes à época da apresentação do projeto preliminar em diante, seja o lugar marginal que ocupa na historiografia jurídica apresentou-se como um desafio. Para compreender melhor a questão, há de se reconstruir o quadro ao momento da tramitação da delegação legislativa.

Alfredo Rocco foi o primeiro a dizer que o objetivo da delegação não era substituir o código vigente, garantindo que se tratava de "retoques" ao texto original (ROCCO, 1927, p. 217-218). Entre os deputados, os relatores Alfredo De Marsico (penalista) e Gino Sarocchi utilizavam termos como "reforma", "emendar", "retoques", "aperfeiçoamento", mas nunca "novo código". Entre os senadores, Mariano D’Amelio utilizou de linguagem dúbia, prenunciando que a reforma seria "uma grande inovação".

Em 1927 surgiu o projeto preliminar, e não se escutou nenhuma voz dissonante. Na promulgação do código, ninguém mais fazia menção ao conteúdo do texto da delegação. A historiografia jurídico-penal ainda não se lançou a fundo sobre o problema. Como já justificado desde o início, a tese é de que o governo, ao lançar uma reforma que tratava de tantos institutos encontrava-se explícito o advento não de uma reforma pontual, mas sim de uma nova codificação ${ }^{15}$. Enquanto Giuliano Vassali releva tal mudança de programa, para Neppi Modona e Pelissero ${ }^{16}$ há uma latente dissimulação de Alfredo Rocco entre o tom do discurso reformador,

15 "Un simile ventaglio di questioni nodali consentiva, evidentemente, ben più che un aggiornamento tecnico del sistema normativo esistente. Il cammino della riforma fu lesto e sbrigativo" (SBRICCOLI, 2009, p. 956); "Formalmente la delega era per modificare il codice, ma nella sostanza era per rifarlo, data l'ampiezza con cui venne formulata" (VINCIGUERRA, 2010, p. XVI).

16 "A una lettura più attenta della legge di delegazione risulta però che i temi destinati ad essere oggetto di modifiche sono assai vasti e incisivi [...] Sulla base di queste premesse, emerge dunque che carattere prioritario della delega è di lasciare carta bianca al governo nell'opera di rielaborazione del codice penale carattere tanto più evidente ove si consideri che manca qualsiasi indicazione dei principî e dei criteri cui dovrà attenersi il legislatore delegato. La sostanziale contraddizione tra il tono dimesso della delega legislativa e l'obiettivo reale di dare al governo la più ampia facoltà di mutare radicalmente il codice 
quando falava nos "ritocchi", e o conteúdo, pois muito mais amplo e claramente oposto ao espírito do código então em vigor. Realizaria na verdade "[...] l'ambizioso programma di dotare il regime di una nuova codificazione penale adeguata ai nuovi assetti politici e istituzionali” (NEPPI MODONA; PELISSERO, 1998, p. 777).

Certo que a amplitude da delegação dada por um frágil parlamento deixaria a entender que estaria se concedendo "carta branca" ao Executivo. Tal interpretação parece prosperar no aspecto instrumental - realmente, o resultado foi que o Governo implantou a reforma a seu gosto - mas esse raciocínio exige considerar que todo o processo legislativo que tramitou por um ano pelas duas casas parlamentares, com inúmeros discursos reiterando sempre tratar-se de uma reforma pontual que atualizaria a grande obra do movimento codificador anterior, não passara de uma grande farsa. Seria ignorar que a oposição ainda que fragilizada naqueles tempos, conseguisse fazer-se ouvir, e por isso mesmo hostilizada; seria considerar que um jurista como Garofalo, para ficar com o exemplo mais eloquente, estivesse a "jogar pérola aos porcos", ao defender a posição até certo ponto surpreendente de manter o Codice Zanardelli (MARQUES, 2007, p. 190).

À época, Luigi Lucchini encampou solitariamente tal luta do front de sua Rivista Penale (SBRICCOLI, 2009, p. 903ss) entre 1925 e 1926, tentando demonstrar que Rocco distorceu os argumentos relativos à comparação com a delegação para o Codice Zanardelli ${ }^{17}$. Fato relevante é que Lucchini, como senador, foi convidado para fazer parte da comissão desta casa parlamentar para a análise do projeto de delegação. Todavia, declinou do convite justamente por discordar do método de concessão dos

penale caratterizza anche la Relazione sulla legge-delega del guardasigilli Rocco" (NEPPI MODONA; PELISSERO, 1998, p. 777-778).

${ }^{17}$ Não só Rocco como D'Amelio, relator-geral da delegação no Senado: “E' vero che le Commissioni parlamentari dovranno limitarsi a dar pareri e non potranno modificare il testo dei codici proposti; ma anche per il codice di commercio, per quello penale e per quello di procedura penale su ricordati, il Parlamento si limitò a fare delle raccomandazioni, che non sempre gli onorevoli Zanardelli e Finocchiaro-Aprile accolsero. La vostra Commissione, per altro, ha creduto che una maggiore discussione circa il metodo proposto per la riforma dei codici non fosse opportuna" (LUCCHINI, 1928, p. 184). 
poderes ao Executivo (LUCCHINI, 1925, p. 58) ${ }^{18}$. Ele já expunha tal situação quando da delegação para os códigos de direito privado ${ }^{19}$ ao governo fascista. Preocupava-se com as diretivas da delegação, especialmente porque às comissões parlamentares caberia apenas um parecer opinativo (LUCCHINI, 1925, p. 355). Seu posicionamento fez Rocco referir-se a ele como adversário. Esta situação foi por ele ironizada, dizendo-se um "amigo sincero" do governo na medida em que faz críticas de quem deseja uma reforma eficaz e não se perdem em elogios vazios (LUCCHINI, 1925, p. 482).

Por fim, no começo de 1926 escreveria com tintas muito fortes seu derradeiro libelo sobre a reforma (LUCCHINI, 1926, p. 101ss). Esta deveria seguir os cânones legislativos não só por amor à forma, mas por respeito à constituição e como forma de mobilizar as instâncias responsáveis. Recorda o zelo do ministro Zanardelli em cumprir estritamente a delegação para os últimos reparos ao projeto de código, respeitando a vontade parlamentar. Exemplar o caso da pena de morte, em que a Camera dei Deputati fez uma votação especial sobre o ponto. No caso do Codice Rocco, bastou a delegação falar em enrijecimento de pena para que se pudesse inserir largamente a pena de morte. A participação parlamentar ao longo do processo legislativo do Codice Zanardelli foi algo muito mais amplo do que um parecer(LUCCHINI, 1926, p. 101-102). Finaliza a parte sobre o método da reforma fazendo elogios a Garofalo por sua postura serena, mesmo sendo politicamente favorável ao governo e cientificamente contra os postulados do Codice Zanardelli (LUCCHINI, 1926, p. 103). Tal episódio, que simbolicamente uniu um expoente "clássico" e

\footnotetext{
${ }^{18} \mathrm{O}$ que nos faz desconsiderar a informação obtida em Marques (2007, p. 202).

19 "Ma rimane poi sempre la questione della procedura legislativa, che spoglia completamente il Parlamento e con esso il paese di qualsiasi efficace e diretta cooperazione, di qualsiasi controllo nell'elaborazione nientemeno che dei codici, i caposaldi, le pietre angolari della legislazione e ne affida la confezione completa e irresponsabile al Governo. Il quale nominerà bensì delle Commissioni, di cui naturalmente faranno parte $\mathrm{i}$ parlamentari più remissivi e compiacenti, sempre però a titolo semplicemente consultivo - essendo poi troppo noti l'indole e il destino di tutte le Commissioni legiferative, per quanto anche composte di buoni elementi” (LUCCHINI, 1924, p. 90).
} 
outro positivista pode ser caracterizado como o crepúsculo da penalistica civile para um longo período de recolhimento da ciência penal italiana ${ }^{20}$.

De outro norte, uma esperada crítica que não veio a ocorrer. Enrico Ferri, mesmo vendo que a aprovação de tal delegação encerraria a discussão sobre o seu projeto de 1921, resignou-se a laurear a iniciativa do Governo. As razões não são explícitas, mas se pode vislumbrar, de um lado, a percepção realista de que o acolhimento pela delegação das questões relativas às medidas de segurança e delinquência habitual seriam vitórias, como enfatiza a redação da revista Scuola Positiva por ele capitaneada (NOTA DI REDAZIONE, 1925, p. 254-255) ${ }^{21}$. Todavia, não deixou de comentar seu desapontamento com o fato de que a reforma a ser realizada seria feita pontualmente sobre o Codice Zanardelli e não pela feitura de um novo código ${ }^{22}$. De outro lado, porque já num momento decadente tenta a cada momento alinhar-se mais ao fascismo, tentando associar a reforma de Rocco aos postulados do positivismo ${ }^{23}$.

${ }^{20}$ Essa "união" entre Lucchini e Garofalo demonstra a eficácia da categoria penalistica civile de Mario Sbriccoli (2009, p. 493ss). Veja-se ainda em Sbriccoli (2009, p. 591ss e p. $1.001 \mathrm{ss}$ ) o papel que a ciência penal assumiria dali em diante, quando vislumbra o renascimento de uma penalistica civile no pós-guerra.

21 Interessante que até ali Ferri pressupunha uma nova codificação: "In conclusione, noi crediamo che l'amore alle nostre idee ci faccia velo se affermiamo che le benemerenze di un progetto Rocco di codice penale saranno maggiori o minori, a seconda che la nuova codificazione soddisferà più o meno compiutamente le esigenze riformatrici della scuola positiva". A Rivista Penale não deixou de fazer escárnio, estranhando tal posicionamento, apesar de regozijar o fim de qualquer possibilidade de sobrevivência do Projeto Ferri (LA DIREZIONE, 1925, p. 476-477).

22 "In sostanza, dunque, sul terreno pratico vi è accordo tra il Progetto e le proposte del ministro Rocco. E la mia sola riserva è che, innestando queste riforme pratiche sul vecchio tronco del codice penale, inspirato ad altri principii direttivi, i risultati nell'applicazione pratica potranno essere meno efficaci. Comunque, io auguro sinceramente che, una volta stabile per legge le proposte dell'on. Rocco, la loro applicazione de i loro risultati vengano ad eliminare questa mia previsione di riserva" (VARIETÀ, 1925, p. 393).

${ }^{23}$ Conforme Ferri (1928, p. 814 e 829), “Il progetto Rocco quindi è l'espressione naturale di queste tre condizioni storiche: le due scuole criminali in Italia e dovunque - le misure di sicurezza ormai inevitabili in una legislazione penale - e la tendenza ad assicurare i prodotti della rivoluzione fascista [...] per tutte le ragioni che ho avuto occasione di esporvi finora, che io arrivo alla mia conclusione finale, che è molto semplice: il Progetto Rocco - tranne il principio di responsabilità legale - accoglie e riproduce le conclusioni 
A reforma levada a cabo pelo fascismo, apesar dos méritos de cunho técnico já amplamente discutidos nesses seus 80 anos de vigência, não deixou de ser maculada pela escolha de um método sem a possibilidade de controle parlamentar. Recente historiografia demonstrou que o consenso durante a reforma por vezes fora fabricado, como a censura ao parecer da Universidade de Sassari quanto ao sistema de penas, retirado para a publicação do volume de pareceres das faculdades nos Lavori (MARQUES, 2007, p. 197-198).

Tal método estava destinado a perdurar durante o fascismo. Assim, a dita "reforma constitucional" feita pelas leis sobre a faculdade do Poder Executivo de emanar normas jurídicas e sobre os novos poderes do Chefe de Governo, com suas medidas restritivas para a iniciativa de projetos de lei pelo Parlamento, tudo isso acabou por tornar o parlamento italiano um órgão meramente consultivo. O golpe final viria em 1936 com a dissolução da Câmara dos Deputados e sua substituição pela "Camera dei fasci". Era o regime do "Capo del governo" 24 , personalizado na figura de Mussolini reunindo materialmente em si as atribuições de governo e legiferação.

Em 1930, o novo código traidor da delegação apresentou-se muito mais radical, pensando apenas na repristinação da pena de morte induzida pela nova visão quanto aos crimes contra o Estado como adaptação ao novo momento político, que resultou na "fascistização" da legislação penal, inserindo a lógica de exceção dos Provvedimenti per la difesa dello Stato na nova codificação.

\subsection{Brasil: usurpação da competência legislativa pelo Executivo}

A Constituição brasileira de 10 de novembro de 1937, que inaugurou o Estado Novo modificou radicalmente o processo legislativo brasi-

della Scuola Positiva in ordine al delinquente e quindi, per le condizioni storiche che rappresenta, per i criteri fondamentali a cui si è indirizzato, conserva all'Italia il primato millenario nella scienza e nelle leggi dei delitti e delle pene".

24 'Le 'leggi fascistissime' in materia di libertà, le tre leggi costituzionali sul governo e sul Gran Consiglio, la legge istitutiva del tribunale speciale per la difesa dello Stato fundavono, dunque, un regime totalitario che fu definito dai costituzionalisti dell'epoca 'regime del capo del governo."' (MERLINI, 1995, p. 46). 
leiro. A iniciativa dos projetos de lei passou a ser atribuição do presidente da república, restando ao parlamento apenas a possibilidade de proposições por iniciativa conjunta de um terço dos membros de uma das casas, desde que versasse somente sobre princípios de legislação ${ }^{25}$.

O controle do Executivo era total, pois o parlamento somente poderia se reunir por convocação do presidente, situação que jamais ocorreu durante a vigência do regime ${ }^{26}$. Assim, toda a legislação do período foi expedida com base numa disposição transitória que dava plenos poderes legislativos ao presidente enquanto o parlamento não fosse instaurado ${ }^{27}$.

Era forte o sentimento de antagonismo à atividade parlamentar ${ }^{28}$, pois esta era vista como sinônimo do momento político superado pela revolução de 1930. Na República Velha, a atividade puramente formal do parlamento não responderia aos anseios da nação ${ }^{29}$. Mais ainda, não co-

${ }^{25}$ Conforme o ministro da justiça do regime, Francisco Campos (2001 [1940], p. 55-56), "A Constituição de 10 de novembro, reconhecendo o mal, deu-lhe o remédio. A iniciativa da legislação cabe, em princípio, ao governo. A nenhum membro do Parlamento é lícito tomar iniciativa individual de legislação. A delegação de poderes não só foi permitida, como se tornou a regra, pois a Constituição prescreve que os projetos de iniciativa do Parlamento devem cingir-se a regular a matéria de modo geral, ou nos seus princípios, deixando ao governo a tarefa de desenvolver esses princípios, e regular os detalhes".

${ }^{26}$ Nem por isso deixou-se à época de propagar o novo método (SEVERIANO, 1938); da mesma forma, ao fim do regime, reapresentava-se o método, agora para demonstrar o quanto ele era mais parecido com as disposições da constituição imperial de 1824 do que as republicanas de 1891 e 1934 (CARNEIRO, 1945).

27 “Conforme escreveram Afonso Arinos de Melo Franco e Raimundo Faoro nos verbetes 'Direito' e 'Constituição' da enciclopédia Mirador, 'a Constituição do Estado Novo não chegou a ser aplicada". Vargas "não quis levar adiante as medidas que a Constituição previa como necessárias à sua entrada em vigor. Preferiu governar indefinidamente, sem qualquer sistema limitativo de seus poderes, atribuindo-lhes uma extensão que o artigo 180 invariavelmente referido, estava longe de conter [...] Mas, agora, tais reverências à legalidade não eram necessárias. $\mathrm{O}$ ambiente mundial as dispensava. Vargas não precisou de muita cerimônia para deixar de aplicar a Carta que ele mesmo outorgara. Daí o fato de o regime do Estado Novo não se dirigir pela Carta de 10 de novembro, aplicada somente na parte que previa a outorga de poderes excepcionais ao presidente da República", (MALIN, 2016).

${ }^{28}$ É vasta a literatura do período sobre o tema. Veja-se, por exemplo, Gil Duarte (1941).

29 "Em conseqüência da expansão da área dos antagonismos e da crescente intervenção das massas nos negócios públicos, a solução dos problemas políticos, econômicos e 
laborava com a atividade legislativa de iniciativa do governo ao emendar os projetos de lei a ponto de deformá-los, seja por incapacidade técnica como para o atendimento de interesses pessoais ${ }^{30}$.

Por essas razões, segundo o Ministro da Justiça Francisco Campos, o governo preferiu utilizar-se do expediente técnico para a condução da atividade legislativa. Assim, o Ministério da Justiça tornou-se a central legislativa do novo regime. Entrevistado em abril de 1939 sobre as leis no Estado Novo, o ministro Campos enfatizou que o "Ministério da Justiça vem trabalhando sem cessar, desde a instauração do regime" no campo legislativo e, citando as muitas das leis realizadas - dentre as quais o anteprojeto de código penal - diz que elas "[...] são o testemunho de uma constante atividade legislativa que o ministério tem exercido, quer diretamente, quer participando de comissões especiais" (CAMPOS, 2001, p. 117-118).

Todavia, neste depoimento não constam muitos detalhes sobre a codificação penal ${ }^{31}$. Eles aparecem em outra entrevista, em julho do mesmo ano. Primeiro, o ministro esclareceu ter percebido que seria oportuna a promulgação do código penal, com a confecção já em estado adiantado, junto ao código de processo penal, que iniciou posteriormente. Cada um

administrativos não podia continuar sob a dependência da deliberação do Parlamento, que era a expressão de uma democracia puramente formal [...] [Assim,] restringiu-se a competência legislativa do Parlamento, retirando-se lhe a iniciativa da elaboração das leis e facultando-se a delegação de poderes ao presidente da República, para expedir decretosleis." (MARTINS, 1940, p. 265).

30 "Não só em outros países a legislação direta pelo Parlamento se mostrou impraticável. Entre nós, os seus defeitos estão patentes a todas as vistas. O processo de crivar de emendas, muitas vezes de caráter pessoal, um projeto de lei, é um processo corrente na forma parlamentar de legislação. Os grandes projetos, em que a unidade de princípio e de técnica é qualidade capital, não podiam sair desse processo senão deformados, mutilados e imprestáveis" (CAMPOS, 2001, p. 55). Em outro momento, Campos (2001, p. 150) utiliza o código civil como exemplo dos malefícios do parlamento sobre o trabalho dos juristas: “Apesar de ser uma grande obra, o Código Civil ressente-se de numerosos defeitos técnicos, que não se encontravam no projeto de Clóvis Beviláqua e vieram prejudicar o sistema construído com mão segura pelo eminente jurista".

${ }^{31}$ Apenas a informação de que o "[...] anteprojeto do Código Penal acha-se em última revisão. Terá assim o País uma lei à altura do seu grau de civilização e do seu regime político, em substituição do velho Código de 1890, que já era antiquado, na época em que se decretou, isto é, há meio século" (CAMPOS, 2001, p. 124). 
dos códigos até então seguira estradas distintas. De um lado, o código de processo penal era uma necessidade, haja vista que a constituição de 1891 deixara a lei processual a encargo de cada unidade da federação. Com a mudança de regime, uma nova codificação que desse um sentido único - a "defesa social" - era objetivo do governo. Tal trabalho foi confiado a uma comissão de juristas. A reforma do código penal de 1890, por sua vez, já estava em pauta desde sua promulgação (SONTAG, 2014, p. 253-333). O Estado Novo aproveitou-se de sua liberdade para acelerar tal processo de acordo com sua visão de direito penal. Para tanto, buscou o professor da tradicional faculdade de direito de São Paulo Alcântara Machado para a construção solitária do projeto $^{32}$.

Voltando às palavras do ministro Campos, apesar de ele elogiar muito o anteprojeto de Alcântara Machado - "o melhor projeto de código criminal que até hoje se fez no Brasil" - haveria uma série de inconvenientes que necessitavam de reparação, como a manutenção da série de leis especiais que por sua natureza política ${ }^{33}$ (contravenções, crimes contra a ordem política e social e crimes contra a economia popular, reunidos no código por Machado), porque não seriam compatíveis com o escopo de uma codificação, que era a estabilidade do texto, enquanto aquelas leis necessitavam de constantes atualizações. De outro norte, algumas inovações provenientes da aplicação de postulados do positivismo criminológico exigiriam uma magistratura especializada a qual o governo não dispunha - e talvez não estivesse disposta a proporcionar. Dessa feita, fez-se a convocação da comissão revisora que junto realizou um trabalho de vários meses (CAMPOS, 2001, p. 141-145), até o código tomar a forma pela qual foi publicado.

Não constam no registro do Arquivo Nacional documentos relativos ao desenvolvimento desses projetos de lei. Assim, há apenas relatos do próprio Ministro Campos e daqueles que participaram das comissões,

\footnotetext{
${ }^{32}$ Para um quadro completo do processo da codificação penal de 1940, cfr. Sontag (2009).

${ }^{33}$ Sobre esse ponto específico, cfr. Dal Ri Jr. (2006) Nunes (2014).
} 
além da literatura jurídica que apoiava o regime a elogiar os "laboratórios" e "oficinas" de criação do direito ${ }^{34}$.

Francisco Campos fez questão de enfatizar o papel decisivo do presidente na atividade legislativa do ministério da justiça. Tudo passava por ele antes e depois do trabalho das comissões, muitas vezes sendo ele mesmo e o ministro a deliberarem sobre que soluções normativas seriam concretamente adotadas $^{35}$. $\mathrm{O}$ ato de legislar era, portanto, sinônimo de reforço da autoridade do regime: "Podem dizer que isso é cesarismo [...] A verdade, porém, é essa - a hora é de ação" ${ }^{36}$. E eram vários os juristas a escrever odes ao presidente Vargas como o legislador supremo da nação,

34 "Mudar uma técnica legal é, quase ( $\mathrm{sic}$ ), que mudar uma forma de governo [...] Transformaram-se, pois, ditas câmaras legislativas, em laboratórios de manufatura legal, onde, além de se escolher, cuidadosamente, todos os elementos substanciais, para a composição da lei, se empregava o máximo cuidado, no estudo apurado do efeito que as leis, assim feitas, iriam produzir, não só no corpo material da nacionalidade, mas, sobretudo, no espírito cultural legal da nova época." (DUARTE, G., 1941, p. 39-40).

35 "Essas leis que, se não perfeitas, são, pelo menos, infinitamente melhores do que os escassos textos de longa gestação que nos dava o Parlamento, provêm de uma ou de outra forma, da vontade do presidente da República: ou como resultado de suas conversações com seus ministros, ou, diretamente, como fruto da sua apreciação dos negócios do Governo. De posse dessa orientação, com freqüência constante de notas do punho do chefe de Estado, e consultadas as fontes de informação, os órgãos de elaboração põem-se em trabalho e, em menos tempo do que levava uma Comissão da Câmara ou do Senado para dar parecer, apresentam o texto à consideração do presidente. É um sistema que foge talvez do padrão usual; mas é um sistema que dá maior rendimento de trabalho, por um custo muito menor" (CAMPOS, 2001, p. 135).

36 “Os que supunham que o Estado Novo, por ser de autoridade e disciplina, perderia as características de um Estado de Direito, devem estar a esta hora surpreendidos com a revolução jurídica que se está processando, no Brasil, após o golpe de 10 de novembro. O Código do Processo, o Código Penal, o Código da Justiça do Trabalho, e as reformas, em estudo, do Código Civil e do Código Comercial, são estruturas novas fixadas de acordo com a evolução do pensamento jurídico e a sua adaptação às condições econômicas, sociais e morais da conjuntura nacional que atravessamos, dentro da ordem, do entendimento e da unidade espiritual do Brasil. Dir-se-ia que só agora, com o regime de 10 de novembro, o Estado brasileiro assumiu, sem mais restrições nem obstáculos, a sua função normativa [...] O Estado para ser a ordem, o comando, a orientação, a disciplina, faz o direito, traça a conduta, impõe as normas, de acordo com as circunstâncias. Podem dizer que isso é cesarismo, ou, com mais elegância, que é oportunismo. Podem dizer o que quiserem os pregoeiros do passadismo, que ainda se aninham, como as corujas, no 
que criava um novo direito para o Brasil, por meio de um ordenamento orgânico e concatenado entre si, dentro do novo espírito nacional (MARTINS, 1940).

Porém, em tom mais comedido, o próprio presidente Vargas atribuía o novo método legislativo como uma necessidade técnica de aprimoramento da atividade tendo em vista a realização de um projeto político que visava enfrentar realmente os problemas da nação ${ }^{37}$. Do mesmo modo, Francisco Campos salientava que relegar o parlamento às questões meramente principiológicas para que o executivo se detivesse sobre questões técnicas era uma questão de modernização administrativa ${ }^{38}$ : esse era o modo com que o ministro entendia ser feita a política do Estado Novo ${ }^{39}$.

pau oco das florestas comidas pelo tempo. A verdade, porém, é essa - a hora é de ação" (MAGALHÃES, 1941, p. 149).

37 "A par das relações novas, oriundas de agentes e sujeitos de direito antes inexistentes, a premência e a celeridade dos fatos sociais exigiram outros instrumentos legislativos, que não as consagradas assembléias políticas. Estas, pela sua composição, pelo seu número, não podiam deixar de ser lentas e pouco eficientes. Os congressos de origem política legiferavam mal, vagarosamente e na verdade delegavam a sua tarefa a comissões de doutos e a advogados de interesses ocasionais. O exame objetivo dessas questões de substância e de forma atesta a orientação realista e moralizadora que levou o novo regime a atribuir a pequenos corpos técnicos e especializados, a função de traduzir em leis os reclamos da coletividade e a salvaguarda das prerrogativas da nação. Todas as reformas até agora feitas não são experiências de teóricos, derivam de inadiáveis problemas e foram orientadas por um pensamento único, uma idéia mestra - o reforço da unidade nacional [...] As leis promulgadas na vigência do Estado Nacional revelam uma vigorosa intenção uniformizadora e a coragem de enfrentar os problemas na sua realidade. Talvez não sejam perfeitas, e não o serão sob muitos aspectos, mas representam a vontade sincera e honesta de estabelecer normas que possas ser respeitadas e cumpridas. As leis inadequadas tornam-se letra morta, mais prejudicam do que beneficiará e geram a descrença na justiça" (VARGAS, 1941, p. 9).

38 “A intervenção ou a ação do Governo pressupõe, porém, num Estado de direito, a legislação [...] A competência natural do Parlamento é a política legislativa; a competência natural do Executivo, a técnica legislativa. Isto é hoje lugar comum não só na ciência política, como na prática das instituições representativas" (CAMPOS, 2001, p. 89-90).

39 "Política? Novidades políticas? Mas o que eu lhe disse já não é política? É política dotar o Brasil de leis claras e justas [...] Tudo isto é política, a melhor política, e essa política é a que vêm praticando todos os órgãos do governo, sob a clara direção do Presidente Getúlio Vargas" (CAMPOS, 2001, p. 160). 
A preocupação com a modernização do Estado, partindo das instituições e chegando à legislação, é uma marca notória do regime de Vargas. Inúmeros são os legados nesse sentido. A questão é que, tratando-se do processo legislativo, valeu a máxima da justificação dos meios pelos fins a serem alcançados. Essa, porém, é uma discussão que não se encerrou com o fim do regime (MELO FRANCO, 1952, p. 17) ${ }^{40}$, tomando cores fúnebres durante a ditadura militar.

\section{Do Legislador-Jurista ao Jurista-Legislador: o papel do juris- ta na atividade legislativa fora do parlamento}

A empreitada de conceder uma veste jurídica a um regime político não é algo simples. O fascismo e o Estado Novo contaram com uma ação sistemática que lhes valeu a possibilidade de modificar o Estado ao passo de poucos anos. No caso da legislação penal, ambos os regimes valeram-se da colaboração de juristas técnicos para a confecção das codificações, uma tradição modificada na medida em que se abandonou o controle final da representação popular.

Todavia, os ditadores Mussolini e Vargas intuíram que haveria a necessidade de uma figura capaz de coordenar tão complexo processo. Surgia, em ambos os regimes a figura do ministro da justiça como o "lawgiver" (FEINBERG, 1970, p. 471-484).

\footnotetext{
${ }^{40}$ Isto porque "[...] a conciliação entre os dois aspectos de um mesmo problema, o técnico e o político, ainda continua a ser a maior dificuldade para o legislador" (CAVALCANTI, 1946, p. 40).
} 
Assim, Alfredo Rocco ${ }^{41}$ e Francisco Campos ${ }^{42}$ assumiram o papel de protagonistas para a construção dos novos regimes. Coordenaram com esmero esse novo modo de legislar. Coincidentemente, uma vez completada a transformação jurídica dos seus respectivos Estados, ambos vêm a ser afastados de seus encargos. Juristas de alta estirpe e de personalidade forte, ambos foram responsáveis pelas reformas constitucionais que tor-

${ }^{41}$ Cfr. D’Alfonso (2004), Ungari (1963) e Marques (2007, p. 161ss). Leia-se a síntese de Vassali: “Alfredo Rocco fu dunque giurista autentico e politico autentico, in proprio. E come tale godette di un rispetto anche dagli estranei al fascismo, compresi coloro che pur deploravano che lo studioso avesse fornito le migliori armi alla dittatura e che fosse giunto non solo a fondare il sistema corporativo e quello costituzionale autoritario, ma a forgiare leggi decisamente liberticide [...] Per l'esattezza dovremmo dire che l'opera di Rocco per il fascismo non fu soltanto un insieme di momenti di reazioni politica ammantati di argomenti giuridici (talora accompagnati da spiegazioni tendenti a renderli più accettabili a coloro che, tanti o pochi, fascisti non erano), ma fu la ragionata costruzione di una dottrina e di un sistema giuridico che costituirono la dottrina giuridica del fascismo e il sistema giuridico fascista [...] Rocco, sì, aveva bene meritato della rivoluzione fascista ed aveva dato a lui, Mussolini, un aiuto nella costruzione dello Stato fascista quale nessun altro sarebbe stato in grado di dargli", (ROCCO, 2005, p. 14-15); e: "Certo si è che quel ministro incise con le sue "riforme", nel bene e nel male (più nel male che nel bene) come nessun altro. E nessun altro ministro si trovò nelle condizioni di tradurre (o veder tradotto) le proprie vedute, anzi la propria ideologia, nella legislazione e nell'amministrazione, con la puntualità, la determinatezza, la competenza, il successo che egli riscosse. Fu un guardasigilli a cui riuscì di trasformare, sia pure per la durata di un ventennio, lo stesso Stato italiano" (ROCCO, 2005, p. 41).

${ }^{42}$ Cfr. Seelaender e Castro (2010, p. 255-291) e Santos (2007, p. 31-48). Leia-se a síntese de Malin (2016): "Definitivamente afastado dos cargos políticos, Francisco Campos permaneceu na presidência da Comissão Jurídica Interamericana até 18 de março de 1955, quando foi substituído por Francisco de San Tiago Dantas. Em seu discurso de saudação a Francisco Campos, San Tiago Dantas afirmou que ele e Rui Barbosa haviam sido 'as duas forças intelectuais mais poderosas que acionaram, entre nós, a cultura jurídica nos últimos 50 anos'. Enquanto a de Rui Barbosa havia operado 'no sentido da elevação dos princípios jurídicos, principalmente dos princípios do liberalismo, à dignidade de um credo social', a de Francisco Campos operara 'no sentido do reexame das construções jurídicas em face das condições sociais e políticas que nelas se encarnam' e abrira o caminho da 'modernização de inúmeras instituições'. Isso através das reformas do ensino secundário e superior e, principalmente, 'escolhendo, modificando, substituindo, registrando e afinal dotando o país de um corpo de leis que, embora elaborado sob um regime político depois repudiado, pôde subsistir praticamente intacto nos quadros legais do Estado democrático restaurado"”. 
naram possíveis transformações que deslocaram os regimes políticos de seus países para dentro do espectro autoritário. Enquanto na Itália a dita "reforma constitucional" passou por modificações na legislação ordinária que davam nova interpretação ao Statuto Albertino sem revogá-lo, o Brasil impôs a fase mais autoritária de Vargas no poder a partir da Constituição de 10 de novembro de 1937 (obra das mãos do próprio Francisco Campos) $)^{43}$.

Importante salientar a intensidade da atividade legislativa levada a cabo por ambos os ministros. Dois são os argumentos principais a justificar tantas modificações no panorama legal. O primeiro, a nível ideológico, diz respeito à necessidade de adaptar o ordenamento jurídico ao novo estágio em que se encontravam as sociedades brasileira e italiana, agora regidas pelo autoritarismo estatal. Aqui os exemplos são inúmeros, mas normalmente evocados em caráter geral. Isso porque o segundo aspecto, de cunho funcional, servia de escudo onde o discurso autoritário tivesse maior dificuldade de penetrar. Argumentava-se que havia a necessidade de produzir muitas leis também pelo fato de que o parlamento há tempos fugira de sua função principal, o que teria ocasionado vácuos legislativos a serem preenchidos (DUARTE, G., 1941, p. 61-62).

O perfil dos juristas colaboradores a tais empreitadas legislativas é bastante delimitado. Não se trata do protagonismo escolástico, de juristas consagrados pela cátedra ou escritos teóricos, mas aqueles envolvidos diretamente com os aspectos "práticos" da legislação. Tanto no Brasil como na Itália, a legitimação pela cátedra também pesou de maneira muito relativa, mas a explicação é diferente: o período que vai de João Vieira até Hungria é não só o período de afirmação do tecnicismo no Brasil, mas, também, do próprio penalista profissional, já afirmado no século anterior na Itália (SONTAG, 2015).

\footnotetext{
43 "Desde fins de 1936, Francisco Campos, acionado por Vargas, adaptava um substitutivo à Constituição de 1934 - que não fora conveniente apresentar durante os trabalhos da Constituinte -, para transformá-lo em projeto da Constituição a ser outorgada após o golpe de Estado. Em meados de 1937, ultimou esse trabalho com a colaboração, entre outros, de Vicente Rao, titular da pasta da Justiça entre julho de 1934 e janeiro de 1937" (MALIN, 2016).
} 
O paradigma tecnicista acabou por predominar no perfil dos juristas escolhidos porque ele dialogava e se fundava com um tipo específico de prática (SONTAG, 2009). Além de essa concepção ser passível de sobreviver sem constrangimentos dentro de um ambiente autoritário, como já muito bem evidenciado por Mario Sbriccoli (2009), a preocupação imediata (senão exclusiva) estava na lei penal e sua aplicação judicial. Não à-toa, a grande maioria dos juristas italianos e a totalidade dos juristas brasileiros envolvidos provinham da magistratura e do Ministério Público ${ }^{44}$. Tal questão foi enfaticamente ressaltada no discurso do Ministro Campos na ocasião da promulgação do código penal brasileiro.

A comissão revisora do código penal brasileiro estava umbilicalmente ligada à comissão elaboradora do código de processo penal ${ }^{45}$, composta por Magarinos Torres - depois substituído por Cândido Mendes Narcélio de Queiroz, Vieira Braga e Nélson Hungria. Esses três últimos, juntamente de Roberto Lyra e Costa e Silva, foram chamados pelo Ministro Campos para uma detida revisão ao projeto de Alcântara Machado para um novo código penal. Dois anos depois, findo este trabalho, restabeleceu-se a comissão para a codificação processual penal que revisaria seu próprio trabalho adaptando-o à nova codificação penal.

Nélson Hungria veio a se tornar o líder dessa comissão. Juiz e professor da capital brasileira conhecido por sua expertise nas ciências penais e a publicação de inúmeros artigos em tom sempre ácido e provocador. Travou com Alcântara Machado um duelo via imprensa acerca de suas preocupações com o anteprojeto, que partiam da nomenclatura perpassando por todos os institutos de parte geral e as modalidades criminosas da parte especial. Tal interesse e visibilidade fez com que fosse chamado para escrever a nova lei do júri. De lá passou para a comissão da codificação processual e por fim o código penal. Além disso, tornou-se o grande expoente do tecnicismo jurídico-penal em terras brasileiras. A sua participação na comissão rendeu-lhe o protagonismo na ciência penal brasileira

${ }^{44}$ Sontag (2009) aprofundará este argumento no sentido de que o "destinatário" da lei penal pela reforma dos códigos seria o juiz, o verdadeiro aplicador da lei.

${ }^{45}$ A melhor reconstrução desse particular, dada a ausência de fontes documentais, é o resumo feito por Narcélio de Queiroz (1943, p. 9) em artigo escrito por ocasião da publicação da nova codificação processual. 
até sua morte, trinta anos depois: escreveu o mais famoso comentário ao novo código, tornou-se ministro da suprema corte e por fim foi o autor de um anteprojeto de reforma ao código (SONTAG, 2009; NUNES, 2014).

Exceção às heterodoxias de Roberto Lyra, que sempre flertara com o positivismo, a comissão tinha como característica principal a linha técnico-jurídica (DUARTE, J., 1941, p. 24 e 26), conduzida pelos magistrados tendo Nélson Hungria como principal defensor. De fato, Hungria (1941) enamorou-se brevemente com o Estado Novo (talvez fruto do reconhecimento alcançado por seu papel na comissão) e manteve-se fiel aos postulados do tecnicismo jurídico ${ }^{46}$.

$\mathrm{Na}$ Itália, o trabalho dos juristas teve como protagonista Arturo Rocco, irmão do ministro, mas já há muito tempo penalista de renome. Estavam à disposição os penalistas de mais alto escol desde que aliados ao regime. Todavia, Alfredo Rocco demonstrou-se crescentemente interessado pela obra que estava capitaneando, de modo a deixar marcas próprias no trabalho reformador. Toda uma geração de penalistas floresceu durante os anos do fascismo, seja de juristas adeptos ao regime, sejam aqueles que utilizavam o tecnicismo como escudo. Quanto a esse comportamento de manter le mani nella pasta e gli occhi al cielo, que se por um lado permitiu a sobrevivência de uma ciência do direito penal minimamente independente do regime, de outra parte não só foi a ele conivente como proporcionou um processo de empobrecimento cultural que levaria décadas para ser restaurado (SBRICCOLI, 2009).

Um possível lado positivo dessa delegação a juristas técnicos seria o fato de o processo legislativo ter levado em consideração o aplicador da lei, se bem que na presente experiência tal contorno tomou dimensões exageradas, especialmente na brasileira, com um número tão reduzido de participantes no processo. Saindo dessas experiências autoritárias sem se esquecer de suas lições, numa perspectiva democrática percebe-se que o mundo dos juristas é um setor que merece uma participação ativa, mas não exclusiva (VINCIGUERRA, 2010, p. XIX-XX; SONTAG, 2009; BAUMAN, 2010).

46 Sobre tais movimentações teóricas nos periódicos jurídicos da época, cfr. Silveira (2013) e Prando (2013). 


\section{Conclusão}

A historiografia já havia demonstrado que o tecnicismo jurídico-penal no campo doutrinário foi capaz de produzir grandes mudanças no direito penal. O presente trabalho fornece uma pequena mostra de como essa dimensão pode ser ampliada quando o que está em jogo não é mais apenas a interpretação do direito, mas a lei que o cristaliza. Os regimes de força brasileiro e italiano souberam empregar isso a seu favor, utilizando a maleabilidade do tecnicismo para dar conta da demonstração de forças do autoritarismo com reformas penais.

Nesse sentido, o direito penal foi um espaço privilegiado, pois é por ele que o Estado tem a maior possibilidade de exercício de controle sobre os indivíduos. Reconstruir o sistema penal foi algo que ambos os regimes colocaram como prioridade, seja para reforçar a repressão contra os opositores políticos, como também para demonstrar sua adequação com a moderna dogmática jurídica que se vislumbrava ao período.

Mesmo que o conteúdo eminentemente autoritário dessas leis seja discutível em alguns casos, para esses regimes a imposição da lei ao seu modo já era demonstração suficiente de força. O meio para tanto foi desprezar o parlamento e avocar para o Governo a legitimidade da atividade legislativa e fazer a Lei ser irrestritamente respeitada. $\mathrm{O}$ autoritarismo, no caso das codificações penais, fascista e estadonovista, se valeu do legalismo para seu respeito.

A participação de juristas renomados ofereceu uma cobertura capaz de inebriar os ânimos quanto aos meios empregados, uma vez que as codificações penais brasileira e italiana são reconhecidas como de alto nível técnico, a ponto de manterem-se em vigor - mesmo com as reformas do pós-guerra em diante - até o presente momento, com marcas subterrâneas de sua genealogia autoritária que continuam a circular pelo direito penal. 


\section{Referências}

ATTI parlamentari della Legge 24 dicembre 1925, n. 2260, che delega al Governo del Re la facoltà di emendare i Codici penale e di procedura penale. In: ITALIA. Ministero della Giustizia e degli Affari di Culto. Lavori preparatori del Codice penale e del Codice di procedura penale. v. I. Roma: Provveditorato Generale dello Stato Libreria, 1928. BAUMAN, Zygmunt. Legisladores e intérpretes: sobre modernidade, pós-modernidade e intelectuais. Rio de Janeiro: Zahar, 2010.

BETTIOL, Giuseppe. Istituzioni di diritto e procedura penale. Padova: CEDAM, 1966.

BIGNAMI, Marco. Costituzione flessibile, costituzione rigida e controllo di costituzionalità in Italia (1848-1956). Milano: Giuffrè, 1997.

CALAMANDREI, Piero. La funzione legislativa sotto il fascismo. In: BOBBIO, Norberto (Org.). Scritti e discorsi politici: Piero Calamandrei. V. II. Firenze: La Nuova Italia, 1966. p. 261-297.

CAMPOS, Francisco. O Estado nacional: sua estrutura, seu conteúdo ideológico. Brasília, DF: Senado Federal, [1940] 2001.

CARNEIRO, Levi. Sentido da reorganização nacional. Revista Forense, [S.l.], setembro, 1945.

CAVALCANTI, Temístocles Brandão. Considerações sobre a elaboração legislativa. In: Revista Forense, [S.l.], Maio, 1946

LUCCHINI, Luigi. Avversario politico del Governo? Rivista Penale, [S.l.], ano V, n. CII, 1925.

LUCCHINI, Luigi. La riforma dei codici. Rivista Penale, [S.l.], ano V, n. XCIX, 1924.

DAL RI JR., Arno. O Estado e seus inimigos: a repressão política na história do direito penal. Rio de Janeiro: Revan, 2006.

D'ALFONSO, Rocco. Costruire lo Stato forte: politica, diritto, economia in Alfredo Rocco. Milano: F. Angeli, 2004. 
DUARTE, Gil. A paisagem legal do Estado Novo. Rio de Janeiro: José Olympio, 1941.

DUARTE, José. O novo código penal. Revista Forense, [S.l.], agosto, 1941.

ESPOSITO, Carlo. La validita delle leggi: studio sui limiti della potesta legislativa, i vizi degli atti legislativi e il controllo giurisdizionale. Padova: Cedam, 1934.

FEINBERG, Barbara Silberdick. Creativity and the Political Community: The Role of the Law-Giver in the Thought of Plato, Machiavelli and Rousseau. The Western Political Quarterly, Utah, v. 23, n. 3, Sep., p. 471-484, 1970.

FERRI, Enrico. Il progetto Rocco di codice penale italiano. In: Principii di diritto criminale: delinquente e delitto nella scienza, legislazione, giurisprudenza: in ordine al Codice Penale vigente, progetto 1921, progetto 1927. Torino: UTET, 1928.

HUNGRIA, Nélson. O direito penal no Estado Novo. Revista Forense, [S.l.], Janeiro, 1941.

LA DIREZIONE (LUCCHINI, Luigi). Riforma dei codici penali. Rivista Penale, [S.l.], ano V, n. CII, 1925.

LATINI, Carlotta. Governare l'emergenza: delega legislativa e pieni poteri in Italia tra Otto e Novecento. Milano: Giuffrè, 2005.

LUCCHINI, Luigi. Riforma dei codici: codice penale e codice di procedura penale nella Relazione del ministro. Rivista Penale, [S.l.], ano V. n. II, 1925.

LUCCHINI, Luigi. Riforma dei codici: le Relazioni senatoriali Garofalo, De Blasio e Stoppato. Rivista penale, [S.l.], ano V, n. CIII, 1926.

LYRA, Roberto. Direito penal normativo. Rio de Janeiro: José Konfino, 1975.

MAGALHÃES, Agamemnon. O Estado e o Direito. Revista Forense, [S.l.], fevereiro, 1941. 
MALIN, Mauro. Francisco Campos (verbete). Dicionário Histórico Biográfico Brasileiro. Rio de Janeiro: CPDOC/FGV. Disponível em: $<$ http://cpdoc.fgv.br/acervo/dhbb $>$. Acesso em: 23 maio 2016.

MARQUES, Tiago Pires. Mussolini's nose: a transnational history of the penal code of fascism (thesis). Florence: European University Institute, 2007.

MARTINS, Pedro Batista. Getúlio Vargas e a renovação do direito nacional. Revista Forense, [S.l.], novembro, 1940.

MELO FRANCO, Afonso Arinos de. Crise do direito e direito da crise. Revista Forense, [S.l.], ano V, n. 142, 1952.

MERLINI, Stefano. Il governo costituzionale. In: ROMANELLI, Raffaele. Storia dello Stato italiano dall'unità a oggi. Roma: Donzelli, 1995.

NEPPI-MODONA, Guido; PELISSERO, Marco. La política criminale durante il fascismo. In: VIOLANTE, Luciano (Org.). Storia d'Italia: legge, diritto, giustizia - Annali 14. Torino: Einaudi, 1998.

NOTA DI REDAZIONE. Progetto di riforma del codice penale e del codice di procedura penale: relazione del ministro. Scuola Positiva, [S.l.], ano V, n. V, 1925.

PRANDO, Camila Cardoso de Mello. O saber dos juristas e o controle penal: o debate doutrinário na Revista de Direito Penal (1933-1940) e a construção da legitimidade pela defesa social. Rio de Janeiro: Revan, 2013.

QUEIROZ, Narcélio de. O novo código de processo penal brasileiro. Archivo Judiciário, [S.l.], Janeiro, 1943.

ROCCO, Alfredo. Discorsi parlamentari. Bologna: Il Mulino, 2005.

ROCCO, Alfredo. Relazione al disegno di legge delega al governo del re della facoltà di emendare il Codice penale, il Codice di procedura penale, le leggi sull'ordinamento giudiziario e di apportare nuove modificazioni e aggiunte al Codice civile (Camera dei Deputati, seduta del 30 gennaio 1925). In: La trasformazione dello Stato. Roma: "La Voce” Anonima Editrice, 1927. 
ROMANO-DI FALCO, Enrico. Gli elementi politici e sociologici del progetto definitivo di codice penale. Rivista Italiana di Diritto Penale, [S.l.], ano V. n. I, 1929.

SALTELLI, Carlo; ROMANO-DI FALCO, Enrico. Commento teoricopratico del nuovo codice penale. V. I, P. I. Roma: Regia tipolitografia delle Mantellate, 1930.

SALTELLI, Carlo. Potere esecutivo e norme giuridiche: la legge 31 gennaio 1926, n. 100 commentata ed illustrata, con prefazione di Alfredo Rocco. Roma: Tipografia delle mantellate, 1926.

SANTOS, Marco Antonio Cabral dos. Francisco Campos: um ideólogo para o Estado Novo. Locus: Revista de História, Juiz de Fora. v. 13, n. 2, jul.-dez., 2007.

SBRICCOLI, Mario. Storia del diritto penale e dela giustizia: scritti editi e inediti (1972-2007). Milano: Giuffrè 2009.

SEELAENDER, Airton; CASTRO, Alexander de. Um jurisconsulto adaptável: Francisco Campos (1891-1968). In: MOTA, Carlos Guilherme; SALINAS, Natasha (Org.). Os juristas na formação do Estado-Nação brasileiro. São Paulo: Saraiva, 2010. p. 255-291. v. 3. SEVERIANO, Jorge. A lei na nova Constituição. Archivo Judiciário, [S.l.], v. 55, 1938.

SILVEIRA, Mariana de Moraes. Revistas em tempos de reformas: pensamento jurídico, legislação e política nas páginas dos periódicos de direito (1936-1943). 2013. 391 f. Dissertação (Mestrado em História) Universidade Federal de Minas Gerais, Belo Horizonte, 2013.

SONTAG, Ricardo. Código criminológico? Ciência jurídica e codificação penal no Brasil: 1888-1899. Rio de Janeiro: Revan, 2014.

SONTAG, Ricardo. Código e Técnica: a reforma penal brasileira de 1940, tecnicização da legislação e atitude técnica diante da lei em Nelson Hungria. 2009. 161 p. Dissertação (Mestrado em Direito) - Universidade Federal de Santa Catarina, Florianópolis, 2009. 
SONTAG, Ricardo. Scienza giuridica e codificazione penale in Brasile tra Otto e Novecento: dialoghi transatlantici. Mimeo, 2015.

TRENTIN, Silvio. Dallo Statuto Albertino al regime fascista. Venezia: Marsilio, 1983.

UNGARI, Paolo. Alfredo Rocco e l'ideologia giuridica del fascismo. Brescia: Morcelliana, 1963.

VARGAS, Getúlio. O novo espírito da constituição e do direito brasileiro. Cultura Política, [S.l.], 1941.

VARIETÀ. Il pensiero di E. Ferri sulla riforma penale annunziata dall'on. Rocco. Scuola positiva, [S.l.], ano V, n. V, 1925.

VINCIGUERRA, Sergio. Dal Codice Zanardelli al Codice Rocco: una panoramica sulle ragioni, il metodo e gli esiti della sostituzione. In:

VINCIGUERRA, Sergio (Org.). Il Codice Penale per il Regno d'Italia (1930) Codice Rocco. Padova: Cedam, 2010. p. XI-XXXVII.

Diego Nunes é professor adjunto na Faculdade de Direito da Universidade Federal de Uberlândia, doutor em Ciências Jurídicas (currículo História do Direito) pela Universidade de Macerata (Itália), líder do "Ordo iuris" - Grupo de pesquisa em História da Cultura Jurídica (UFU/CNPq).

E-mail: diegonunes@ufu.br

Endereço profissional: Universidade Federal de Uberlândia, Faculdade de Direito, Av. João Naves de Ávila, n. 2.121, Santa Mônica, Uberlândia, MG - 38408-100. 